\title{
Modeling and Parameter Optimization of Dynamic Characteristic Variables of Ballast Bed during Operation for Dynamic Track Stabilizer
}

\author{
Bo Yan $(\mathbb{D}$ and Jingjing Yang $\mathbb{D}$ \\ Kunming University of Science and Technology, Kunming 650500, China \\ Correspondence should be addressed to Jingjing Yang; 20170050@kust.edu.cn
}

Received 16 January 2021; Revised 8 February 2021; Accepted 2 March 2021; Published 11 March 2021

Academic Editor: Rui Wang

Copyright (C) 2021 Bo Yan and Jingjing Yang. This is an open access article distributed under the Creative Commons Attribution License, which permits unrestricted use, distribution, and reproduction in any medium, provided the original work is properly cited.

\begin{abstract}
The high traffic density of railway line causes ballasted track to be extremely busy, and thus it is particularly important to improve the efficiency during railway maintenance. The changing law of dynamic characteristics of ballast bed during operation for the dynamic track stabilizer is conducive to optimize simulation analysis of the vehicle-track system, so as to provide an optimized choice of operating parameters for promoting the pertinence and efficiency of dynamic track stabilizer. This paper presents the acceleration response of vehicle-track-subgrade system during operation of a WD-320 dynamic track stabilizer and proposes the range of effective operating parameters. Then, the influence of operating parameters on the dynamic characteristics of the ballast bed is discussed for searching the optimal operating parameters under the single factor influence. Finally, the change laws including the support stiffness, damping, lateral resistance, and subsidence for the ballast bed are studied, and a parameterized model for dynamic characteristics of the ballast bed which can optimize the selection for operating parameters is constructed, rendering an effective reference variable for improving the simulation accuracy of the vehicle-track coupling system.
\end{abstract}

\section{Introduction}

At present, high speed and heavy loading are the development direction of the railway traffic system, which leads to the extremely busy status of railway transportation. In order to protect the railway system's security, stability, and highspeed operation, both academia and engineers have spent a lot of time and made great effort to study the rail and vehicle vibration problems, resulting in establishment of many analysis theories and methods [1,2]. With the development of the study from an independent and simplified analysis to the coupling, complex, and large random system, the dynamics research of the vehicle-track system also gradually becomes mature [3-5]. At the same time, the quality of the railway line directly affects the safe and high-speed traffic of vehicles, so the maintenance of railway lines should be strengthened. Therefore, the large-scale railway maintenance equipment plays a significant role in railway traffic system.
The common large-scale railway maintenance equipment includes screen cleaning vehicle, tamping vehicle, stabilizing vehicle, and ramming and stabilizing integrated vehicle. However, the simulation and experimental research on such equipment are limited. In this paper, in order to accelerate the development of modern railway construction, we provide some effective references for optimizing the large-scale railway maintenance equipment and improving the operation accuracy, operation efficiency, and track quality.

There are many particles in the ballast bed, which are discrete making the mechanisms of bearing and force transmission very complicated [6]. In general, after the railway maintenance operations such as bottom cleaning and tamping with the large mechanical equipment, the ballast of the ballast bed is not dense enough. After the operations of cleaning, tamping, and stabilizing, the lateral resistance of the sleeper can reach $80 \%$ of the level before railway maintenance; that is, the dynamic track stabilizer can 
quickly improve the quality and the stability of the ballast bed [7]. When a dynamic track stabilizer operates on the complex vehicle-track-subgrade system, multiple factors including the operating parameters of the vehicle and the mechanical characteristics of the ballast bed will affect each other. It is essential to analyze and define the more important evaluation indicators for measuring the effect after the operations and confirming the influence on the quality state for track under different operating parameters, as well as establishing the optimal operating parameters model to maximize the values of the evaluation indicators. These efforts to improve the efficiency and effectiveness of stable operation definitely have significant practical value. In particular, it can provide theoretical references for the optimization and design of the stable device. The lateral resistance and the vertical resistance of the ballast bed are closely related to the stability of the track-subgrade system and track creep $[8,9]$. The running vehicle directly applies dynamic load on the ballast bed through the track structure. Therefore, the dynamic characteristics of the ballast bed are the most critical factor for determining the passing speed of vehicles $[10,11]$. In order to clearly discuss the contact force between the train wheels and the rail during the movement of the vehicle, a vehicle-track-subgrade system model has been constructed in the early work. Then the vibration response of the ballast bed and subgrade caused by the moving vehicle were simulated on the basis of the vehicle-tracksubgrade interaction model [12-17]. Previous studies have found that there is a certain relationship between the geometric irregularity of the track and the settlement of the ballast bed. However, the discreteness and randomness of motion of the ballast make this relationship very complicated, and further in-depth and detailed research is very difficult [18]. The dynamic characteristics are an important index to evaluate the quality of the ballast bed, but they are difficult to obtain. It is a challenge to analyze and study the influence of unequal conditions of the quality for the ballast bed. Chou et al. [19] used the function method to achieve curve fitting and established a regression function model, which provides a good approach and reference for us. The adaptive repetitive learning control and the predefined time sliding mode control proposed by Wang et al. [20, 21] provide good research ideas for us. When the vehicle is passing, the overall state of the ballast bed is relatively no mutation, so the parameter values of the dynamic characteristics are relatively unchanged. After the dynamic track stabilizer passed the line in working, the ballasts are rearranged, and the density also is changed, resulting in a change in the overall state of the ballast bed. Therefore, the parameter values of the dynamic characteristics of the ballast bed will be changed also [22].

In this paper, we study the acceleration response of the vehicle-track-subgrade system during the operation of the WD-320 dynamic track stabilizer and propose the range for operation parameters of effective maintenance working. The structure and principle of dynamic track stabilizer are shown in Figures 1 and 2. Moreover, we also investigate the influence of operating parameters on the status of the ballast bed and put forward the optimal operating parameters

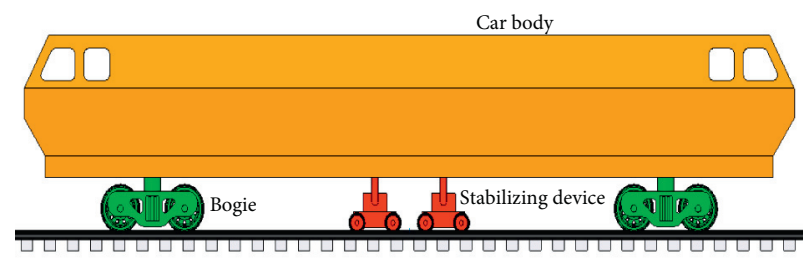

Figure 1: Structure diagram of the WD-320 dynamic track stabilizer.

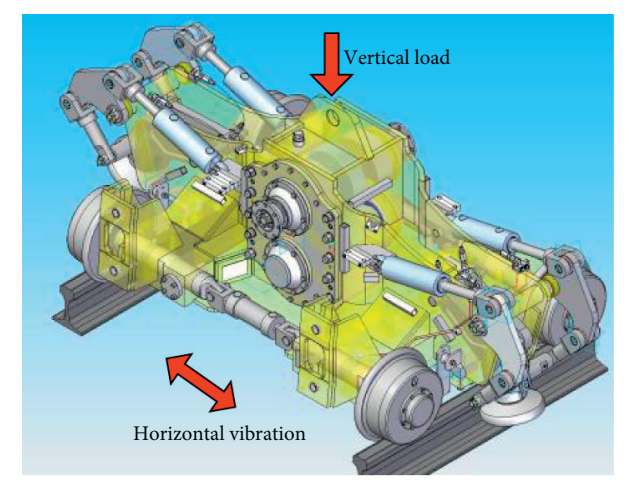

FIGURE 2: The principle of stabilizing device.

under the single factor influence. Finally, the change laws of the support stiffness, damping, lateral resistance, and subsidence of the ballast bed are studied. A parameterized model of the dynamic characteristics of the ballast bed is constructed, which can optimize the selection of operating parameters to improve the efficiency during railway maintenance and effectively solve the problem of less maintenance time caused by high traffic density.

\section{Field Test}

The acceleration and displacement data of the body, bogie, stabilizer, rail, sleeper, and other components of the dynamic track stabilizer in different working parameters are very important dynamic responses. After obtaining the field test response of the dynamic track stabilizer, the measured data are compared with the simulation data to verify the practicality of the mathematical model established before, which is optimized to increase the simulation accuracy. Finally, the mathematical model is applied to the vehicle-track system's simulation, analysis, and optimization design. This paper conducts a more detailed field test. The main test's pieces of equipment are the WD-320 dynamic track stabilizer, two sets of Donghua DH-5922 dynamic signal test and analysis system (including sensors and computers), files, sandpaper, and so forth. The installation of the acceleration sensors is shown in Figures 3 and 4. Finally, the acceleration response data of each component were obtained.

We have gotten some effective opinions and demonstrations through field test and analysis, where the lateral resistance of sleepers is an important indicator and parameter in evaluating the quality state of the ballast bed. By 

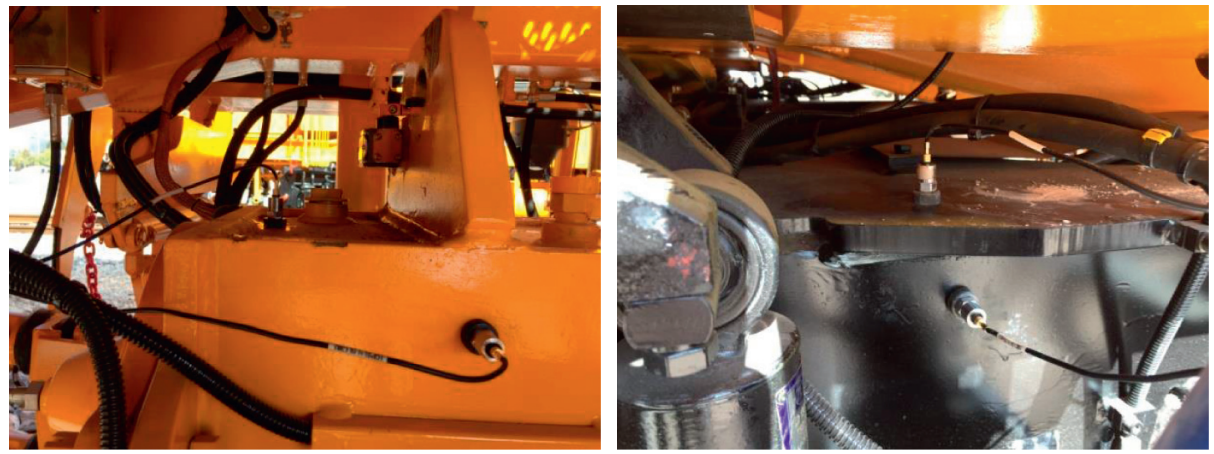

FIgURE 3: Sensor installation on the stabilizing device and bogie.
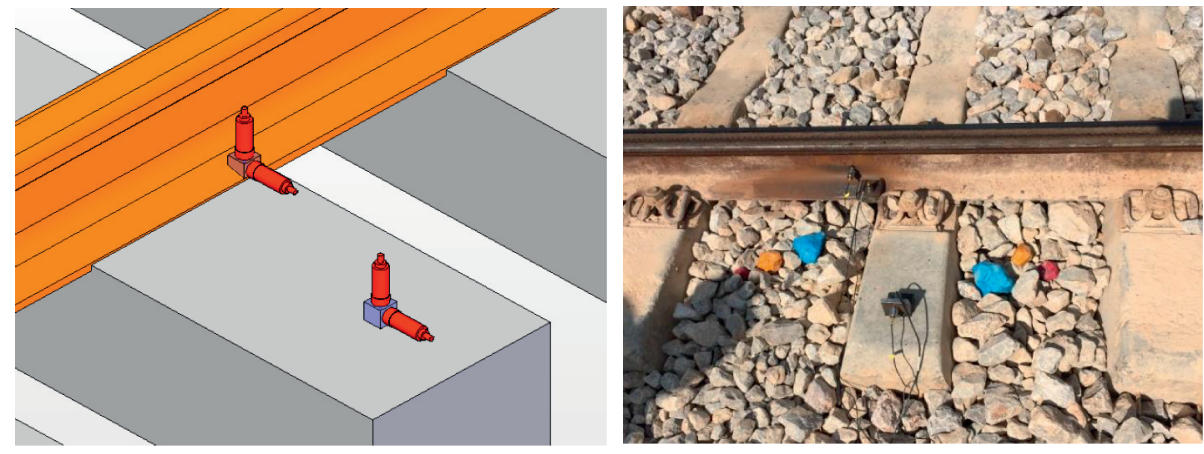

Figure 4: Schematic diagram of sensor installation on the rail and sleeper.

learning from some existing working principles and methods, we designed and manufactured a lateral resistance test device, which can easily get the lateral resistance value of sleepers to study the influence of different operating parameters. The schematic diagram and field test diagram are shown in Figures 5 and 6, respectively.

The test procedure is described as follows. We selected and marked three sleepers close to each other on a railroad and ensured that the ballasts under the sleepers are in similar state. Under a certain parameter, the tamping vehicle starts and passes through the marked sleepers. Then, remove the fasteners of the marked sleepers to separate the sleepers from the rail, and dig up part of the ballast on one side of the sleeper perpendicular to the rail. Subsequently, install the lateral resistance test device. Operate the test device to make the sleepers move $0.5,1,1.5,2,2.5$, and $3 \mathrm{~mm}$ relative to the rail, and record the lateral resistance value of each marked sleeper at that time. After the test of each sleeper is completed, move the sleeper back to its original position. Furthermore, install the fasteners, and backfill the ballast to its original state. Subsequently, let the WD-320 dynamic track stabilizer work on the railway under given working parameters and pass the marked sleepers. Repeat the previous test process: remove the fasteners, install the device, measure and record the resistance value, move back the sleeper, install the fasteners, and backfill the ballast. So far, the different values of the lateral resistance when the sleeper moves at the same displacement in the two tests before and after can be obtained, that is, the change of the lateral resistance of the sleeper before and after the dynamic track

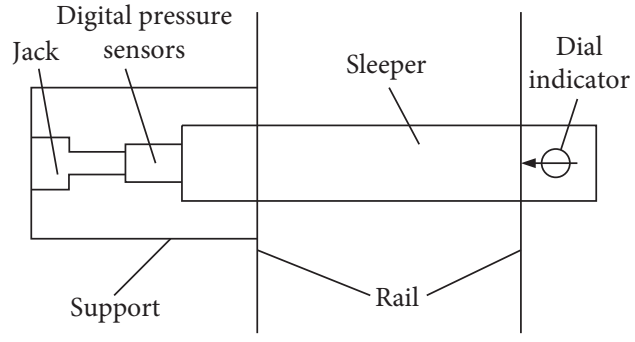

Figure 5: Schematic diagram of device for lateral resistance test.

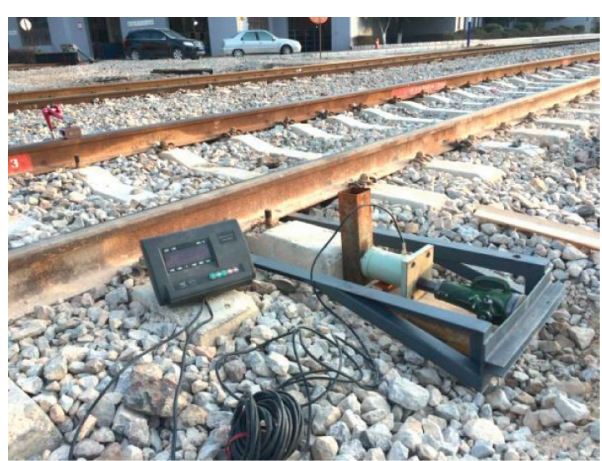

Figure 6: Lateral resistance test of sleeper.

stabilizer passes the railway line under a given working parameter [23]. Finally, after repeating experiments, the lateral resistance values of the sleeper under working with unequal operating parameters are successfully obtained. 


\section{Acceleration Response Analysis}

Through the dynamic signal test and analysis, the dynamic response signals of the vehicle-track system under different operating parameters, including vehicle speed, vibration frequency, and down pressure, are obtained. As shown in Figure 7, the lateral acceleration and vertical acceleration of sleepers versus time are given when vehicle-track system operated at a fixed speed of $1.5 \mathrm{~km} / \mathrm{h}$ and a vibration frequency of $28 \mathrm{~Hz}$ under the pressure conditions of 50, 60, and 70 bar, respectively.

The signal envelope analysis method is utilized to analyze the time-domain signals of the acceleration of each component of the vehicle-track system, which are obtained by field tests for studying the influence of different operating parameters on each component of the system.

The corresponding envelope curves based on the relevant public announcement of envelope calculation have been calculated and drawn, as shown in Figures 8-11.

It has been observed from Figure 10 that when the operating pressure is less than or equal to $60 \mathrm{bar}$, as the operating pressure increases, the acceleration dynamic response of the rail does not change significantly. However, when the operating pressure reaches 70 bar, the acceleration dynamic response of the rail increases significantly and, in particular, has a sudden change. Therefore, for the steel rails, it is not recommended to select the value of pressure greater than or equal to 70 bar as the down pressure parameter during operation. Similarly, the operating vibration frequency should not exceed $30 \mathrm{~Hz}$.

\section{Ballast Bed Quality Status Analysis}

The evaluation indicators and parameters of the quality state of the ballast bed are complex and are affected by many factors, including the particle index characteristics and fouling rate of ballast, the support stiffness and resistance of sleeper, elasticity and permeable performance of ballast bed, density, irregularity of the track, and physical geometry size of ballast bed [24, 25]. The track geometry and position refer to the geometry, relative positions, and basic dimensions of each part of the track. Under the premise of ensuring the track geometry and position, the ballast bed state can be roughly appraised by measuring the lateral resistance [26]. Based on the real-time measurement, feedback, and adjustment of the high-precision measurement system of the large railway maintenance vehicles, the railway line after the maintenance working will have better track geometry and position. In summary, the quality of the track bed can be roughly appraised by comparing the value of the lateral resistance of the sleeper after maintenance working [23].

When the WD-320 dynamic track stabilizer was tested in the field, the vehicle's working speed was set as $1.2 \mathrm{~km} / \mathrm{h}$, $1.5 \mathrm{~km} / \mathrm{h}$, and $1.8 \mathrm{~km} / \mathrm{h}$, the vibration frequency was set as $20 \mathrm{~Hz}, 22 \mathrm{~Hz}, 25 \mathrm{~Hz}, 28 \mathrm{~Hz}, 30 \mathrm{~Hz}$, and $35 \mathrm{~Hz}$, and the pressure was set as $50 \mathrm{bar}, 60 \mathrm{bar}$, and $70 \mathrm{bar}$, respectively. The lateral resistance value in each working state was recorded, and then the changes in the lateral resistance of the sleeper before and after the operation were analyzed. The curves of the increase rate of the lateral resistance of the sleeper after the operation under different vibration parameters are fitted out, as shown in Figure 12.

It can be found from Figure 12 that the lateral resistance value of the sleeper increases a lot after the operation at the vibration frequencies of $18,22,25,28$, and $30 \mathrm{~Hz}$. The lateral resistance value is not increased or the increase is not obvious after operation at frequencies less than $18 \mathrm{~Hz}$ or more than $30 \mathrm{~Hz}$. When a certain value between $18 \mathrm{~Hz}$ and $30 \mathrm{~Hz}$ is selected as the vibration frequency parameter of operation, the quality state of the ballast bed will be improved effectively. It demonstrates that $18-30 \mathrm{~Hz}$ is the effective range of vibration frequency for the WD-320 dynamic track stabilizer. Moreover, when the value of the vibration frequency parameter is between 25 and 30 , the quality state of the ballast bed is significantly improved. The analysis found that the optimal vibration frequency of operation for the dynamic track stabilizer is $28 \mathrm{~Hz}$.

Using the same method for comparative analysis, it can be found that the effective range of pressure for the WD-320 dynamic track stabilizer is $50-70$ bar, and the optimal operating parameter of pressure is $60 \mathrm{bar}$.

The influence of different working speeds on the lateral resistance value is not obvious, so that the difference in the vehicle speed does not affect the quality state of the ballast bed effectively.

\section{Dynamic Analysis of Ballast Bed}

5.1. EDEM Simulation. In recent years, the discrete element method has developed rapidly, and it has become an important method that is widely used in the study of solid particles. Using this method to simulate the working process of a dynamic track stabilizer, the dynamic response characteristics of the vehicle-track-subgrade system can be studied appropriately. In this paper, the software of extended distinct element method (EDEM) was used for simulation analysis. In order to avoid the huge computational workload caused by simulating the entire vehicle-track system, the movement of a sleeper was simply simulated. Five kinds of typical ballast particles were selected, for making the simulation closer to the reality of railway, as shown in Figure 13. We superimposed spheres of different radii to form a complex-shaped composite particle and thereby established an irregular-shaped ballast particle model. Then, the response during operation with different parameters was simulated, and the corresponding dynamic characteristic data of the ballast bed were extracted.

5.2. Lateral Resistance Analysis. According to the simulation data, the lateral resistances of the sleeper when the sleeper moves $0.5,1,1.5,2,2.5$, and $3 \mathrm{~mm}$ were extracted, and then the curves of the lateral resistance under different working conditions were drawn, as shown in Figures 14 and 15.

Figures 14(a)-14(d) show the lateral resistances of sleeper under different conditions, in which the vibration frequencies were fixed at $20 \mathrm{~Hz}, 25 \mathrm{~Hz}, 28 \mathrm{~Hz}$, and $30 \mathrm{~Hz}$ and the pressures were set up as 40 bar, 50 bar, and 60 bar, 

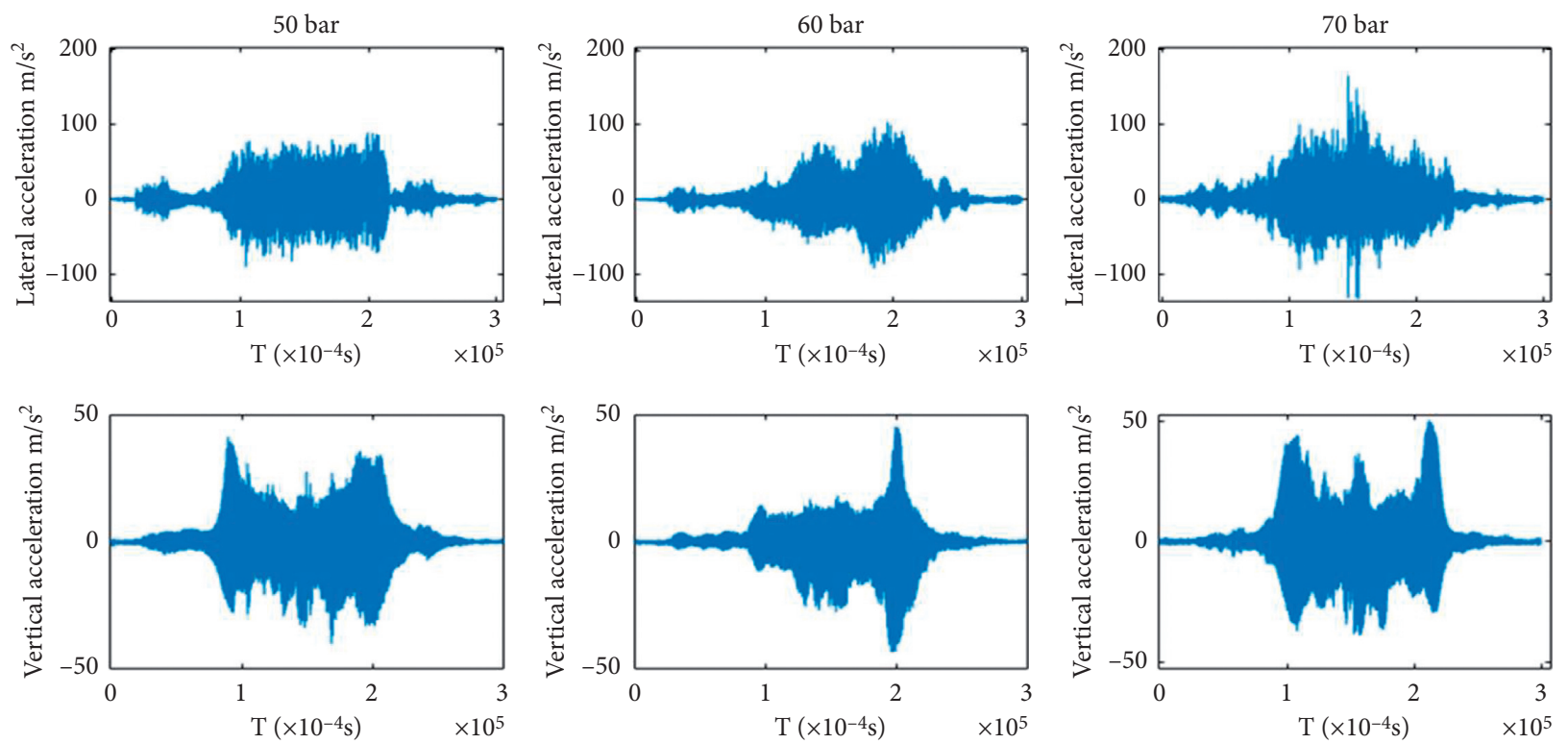

FIgURE 7: Comparison of acceleration of sleeper under different pressures.
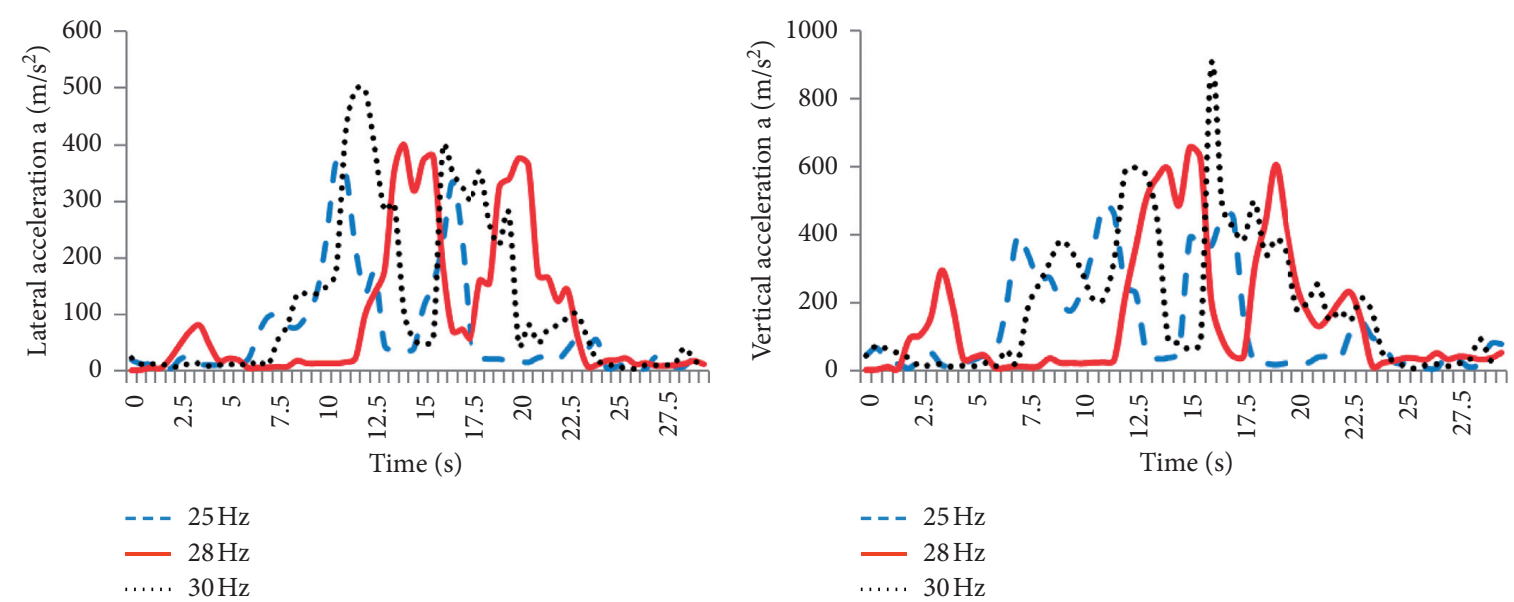

FIgURE 8: The envelope of acceleration of rail under different vibration frequencies.
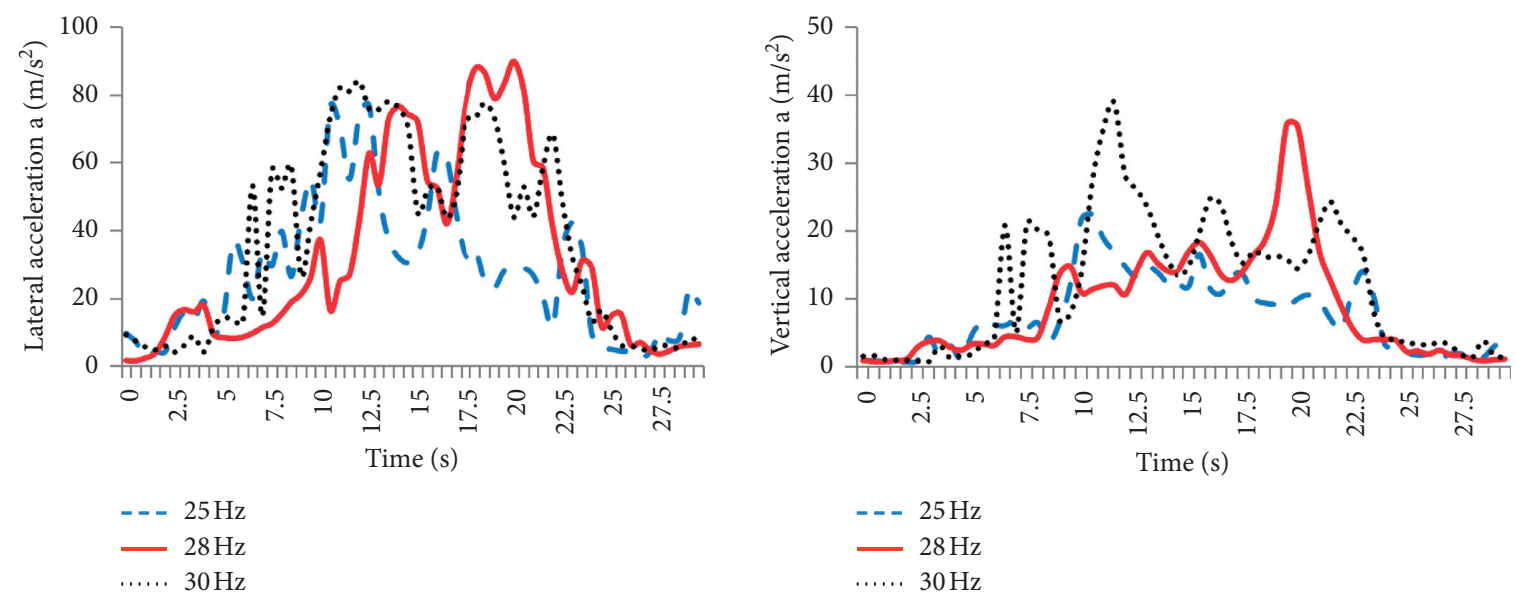

FIgURE 9: The envelope of acceleration of sleeper under different vibration frequencies. 

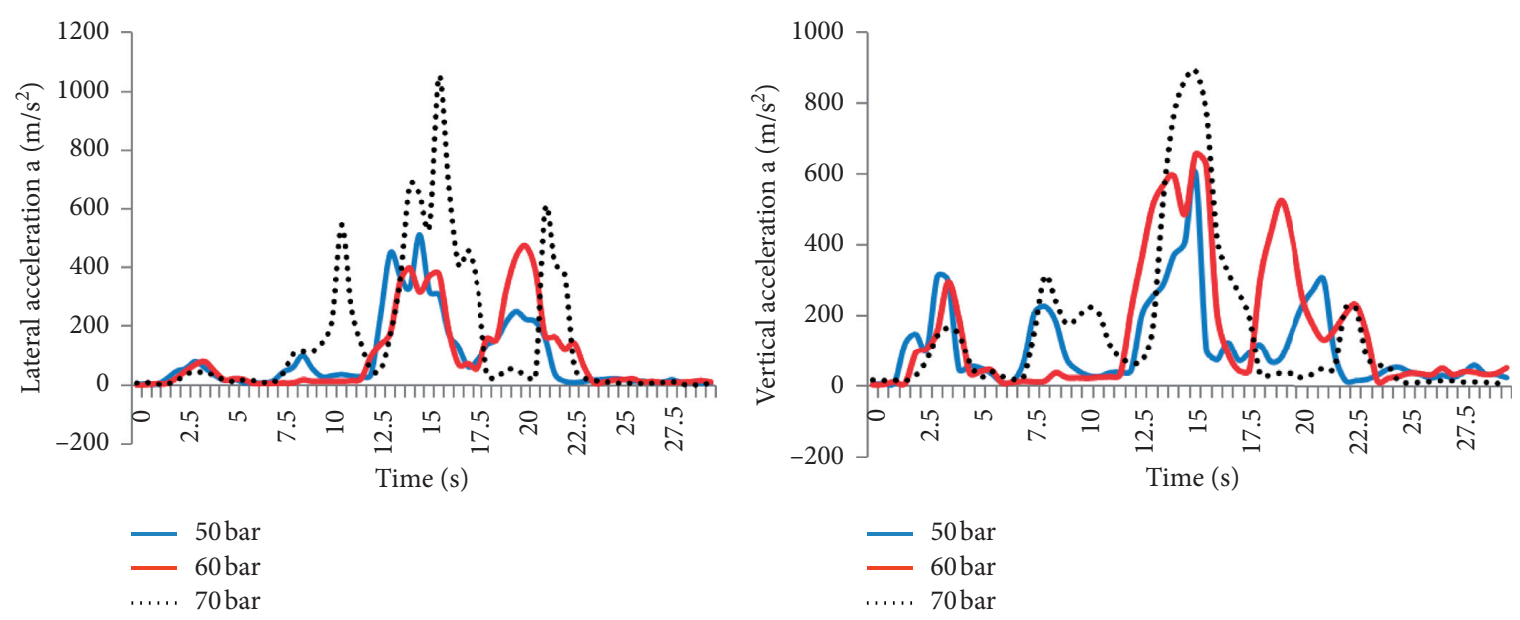

FIGURE 10: The envelope of acceleration of rail under different pressures.
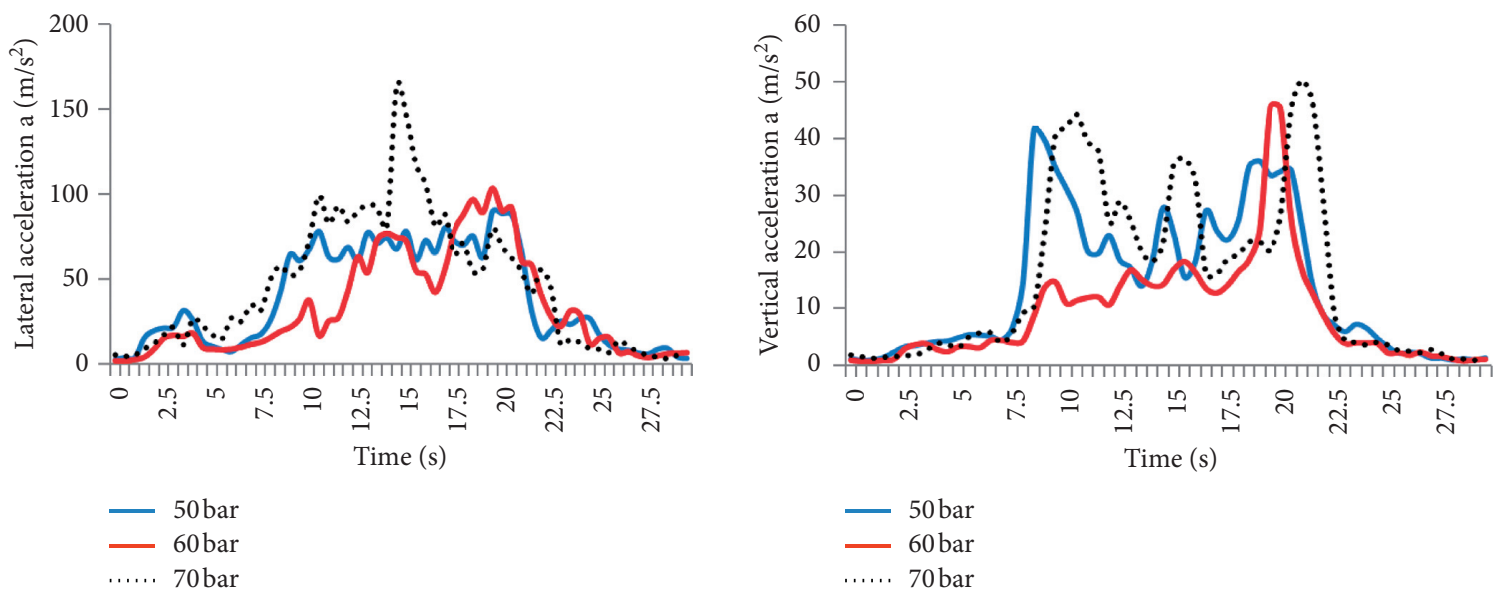

FIGURE 11: The envelope of acceleration of sleeper under different pressures.

respectively. It can be seen from Figure 14 that, after operation in different working conditions under the fixed vibration frequency and different pressures, as the sleeper moves laterally to the same displacement, the lateral resistance value of the sleeper under the 60 bar working condition was always the largest and increased steadily. Therefore, the 60 bar working condition is the optimal pressure for the ballast bed to quickly reach a better quality state. Figures 15(a) and 15(b) show the lateral resistances of sleeper under different conditions that the vibration frequencies were set up as $20 \mathrm{~Hz}, 25 \mathrm{~Hz}, 28 \mathrm{~Hz}$, and $30 \mathrm{~Hz}$, and the pressures were fixed at 50bar and 60bar, respectively. It can be seen that, after operating in different working conditions with the same pressure and different vibration frequencies, the lateral resistance value of the sleeper at $28 \mathrm{~Hz}$ was steadily increased without sudden changes.

In summary, under the operating conditions of $60 \mathrm{bar}$ pressure and $28 \mathrm{~Hz}$ vibration frequency, the lateral resistance of the sleeper increased stably, so that the ballast bed can reach a better quality state quickly. This conclusion is consistent with the factory site.
5.3. Stiffness Influence Analysis. In the discrete element method, the plant model is divided into independent units, and the position of all cells is updated at each time step. By tracking and analyzing the microscopic motion of each element, the macroscopic motion of the entire object is obtained [27]. The damping of the ballast bed and the stiffness of the support sleeper are two important characteristic parameters for studying the dynamic characteristics of the ballast bed.

According to $K=F / \triangle Z$, a constant force is applied to the ballast bed at a certain moment of the simulation analysis, and then the compression amount of the ballast bed is obtained. Finally, the support stiffness of the sleeper at this time is calculated. For a single-degree-of-freedom damped vibration system similar to the entire track bed, the damping can be calculated from the free vibration attenuation curve, which is a common method. According to the differential equations of motion, Euler's formula, and shock experiment data, the damping vibration curve of a single-degree-of-freedom system can be obtained easily [22]. 

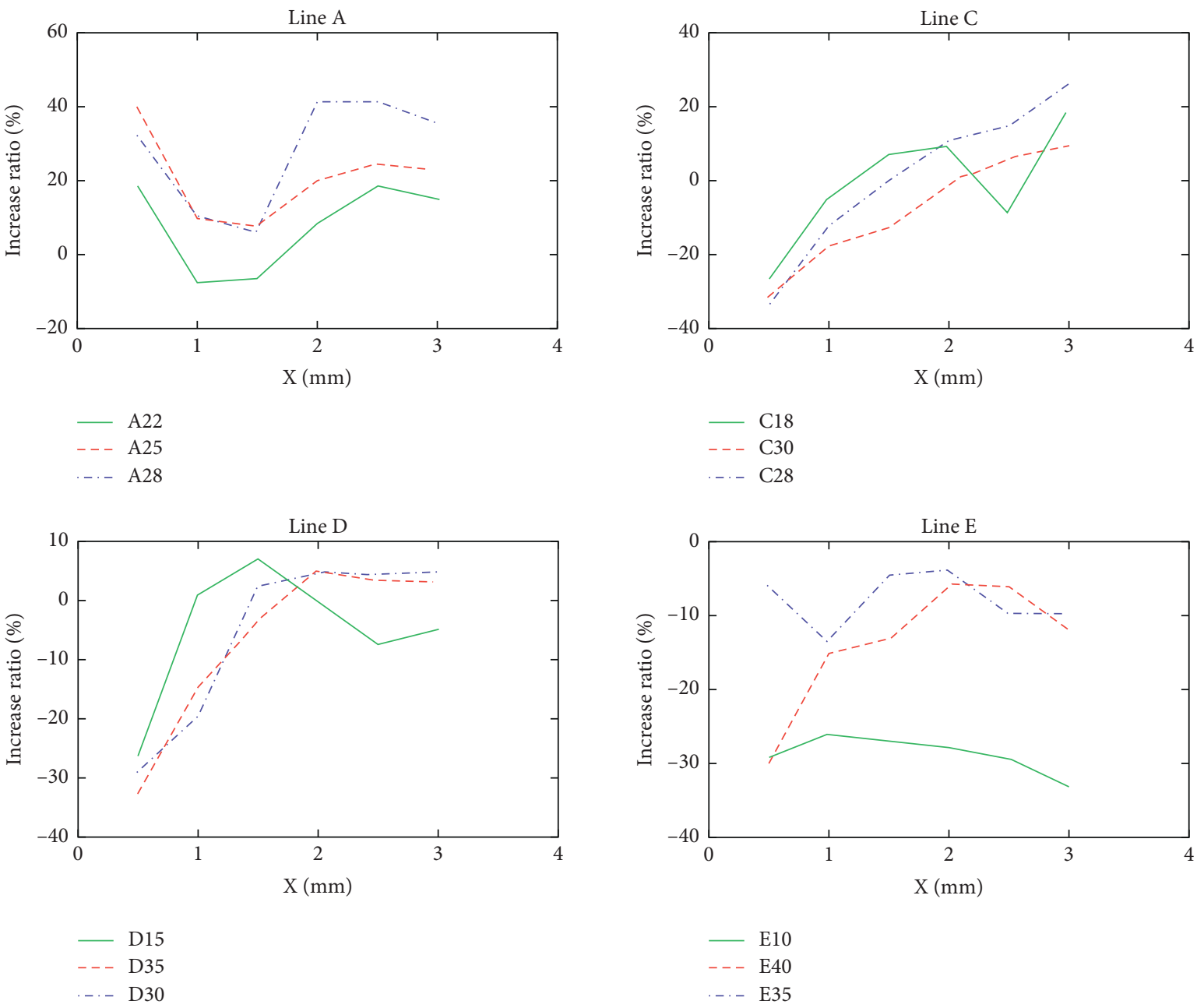

FIgURE 12: Comparison of the lateral resistance.

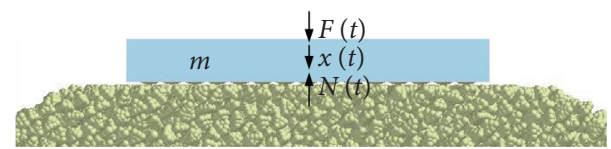

Figure 13: The analysis model of sleeper-track bed system.

Assuming that, in a vibration period, the peak values of vibration displacement were $\mathrm{A} 1$ and $\mathrm{A} 2$, the logarithmic decrement can be expressed as

$$
\delta=\ln A_{1}-\ln A_{2}=\xi \omega_{n} T=\xi \omega_{n} \frac{2 \pi}{\omega_{d}}=\frac{2 \pi \xi}{\sqrt{1-\xi^{2}}} .
$$

Then, according to the above formula, $\xi$ can be calculated. Finally, the value of damping can be obtained as

$$
\begin{aligned}
& \xi=\delta / \sqrt{4 \pi^{2}+\delta^{2}}, \\
& c=2 \xi \sqrt{m k} .
\end{aligned}
$$

The compression amount of the ballast bed at a moment can be found by analyzing the simulation data. Due to the fact that $F=K^{*} \triangle Z$, the supporting stiffness values of the sleeper at the moment can be calculated. Analyze the data and get the attenuation peak values of $\mathrm{A} 1$ and $\mathrm{A} 2$, and then calculate the damping value by formulas (1)-(3). The curve of the settlement of the integrated ballast with the time is shown in Figure 16. The curve of increase ratio of the sleeper support stiffness under different working conditions is shown in Figure 17.

5.4. Mechanical Characteristic Variable Model. In order to reduce the amount of calculation and shorten the calculation time, we simplified the details and conditions when using the EDEM software for simulation. For example, the details of the ballast particles were not refined, and the collision between particles and ballast slip damage was not considered. Therefore, there must be a certain difference between simulation and reality, but it will not affect the result. As 


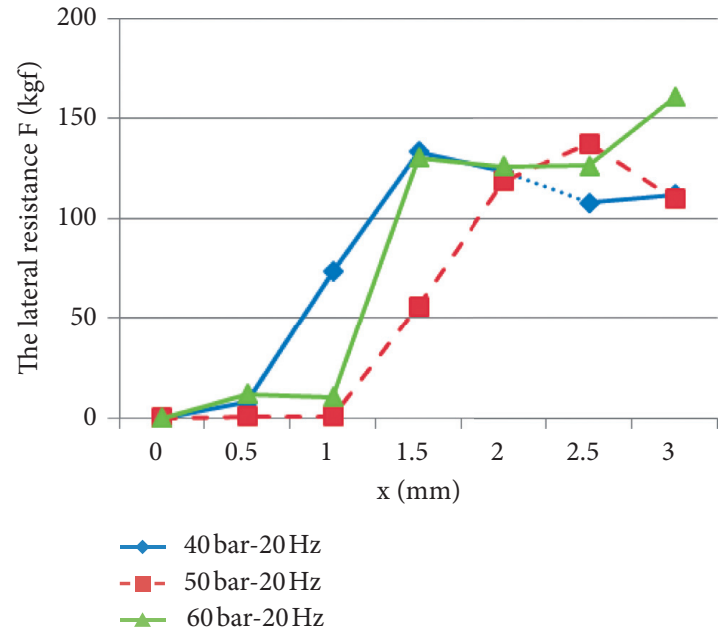

(a)

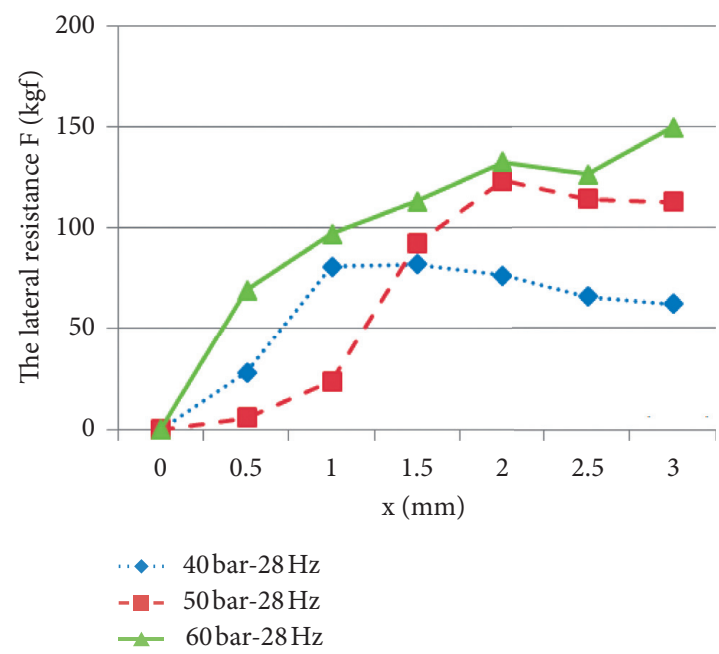

(c)

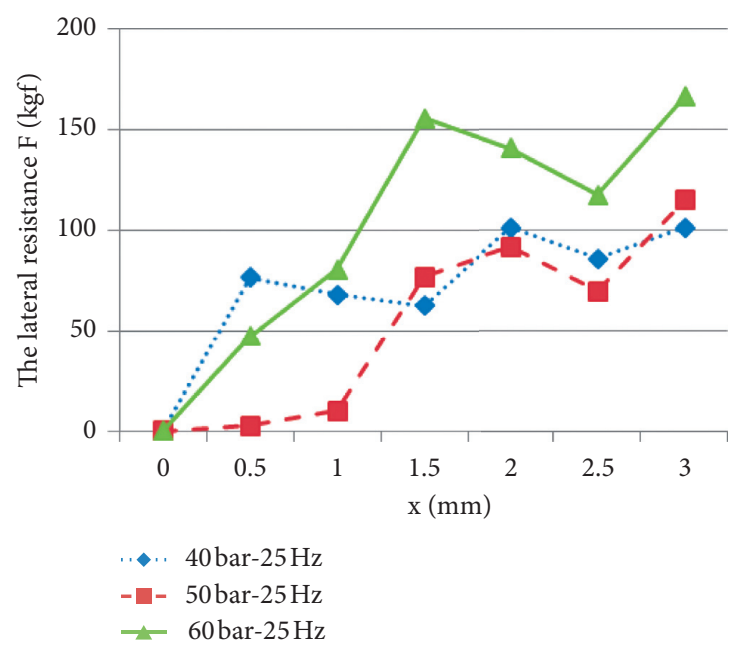

(b)

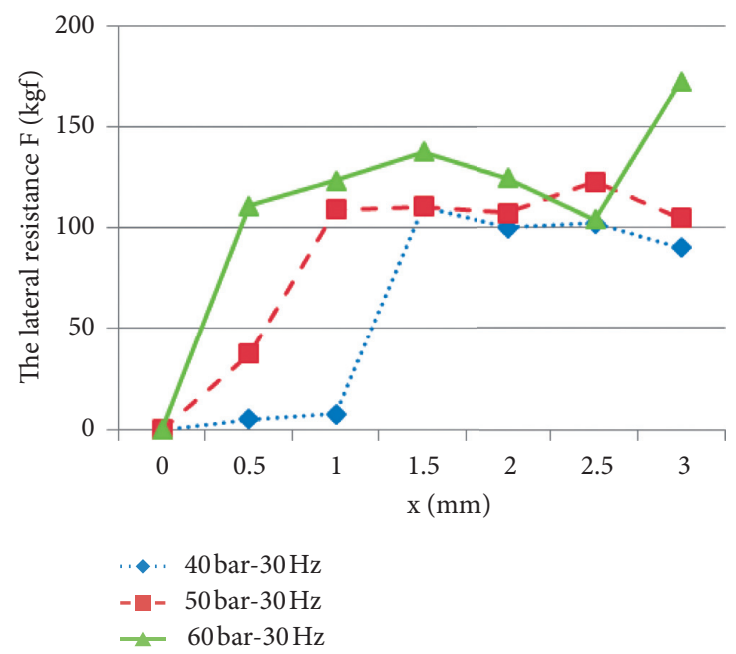

(d)

Figure 14: The curve of the lateral resistance under fixed frequencies and different pressures.

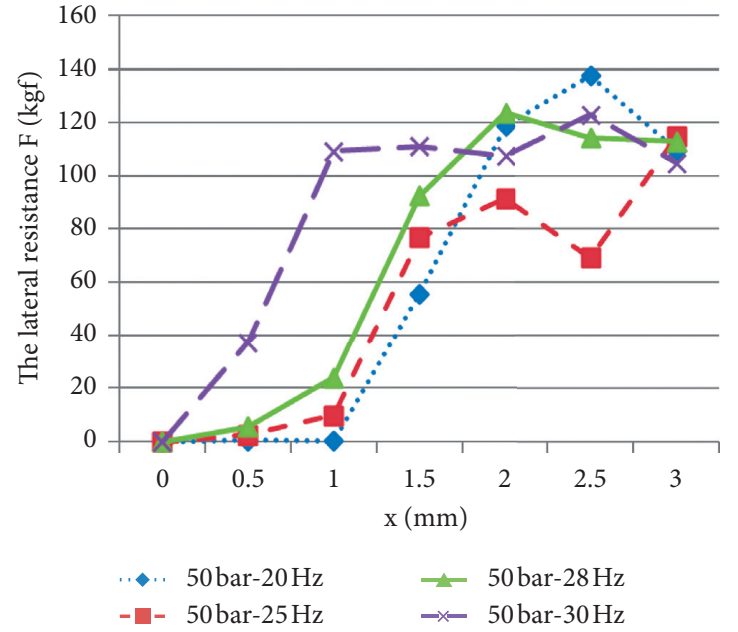

(a)

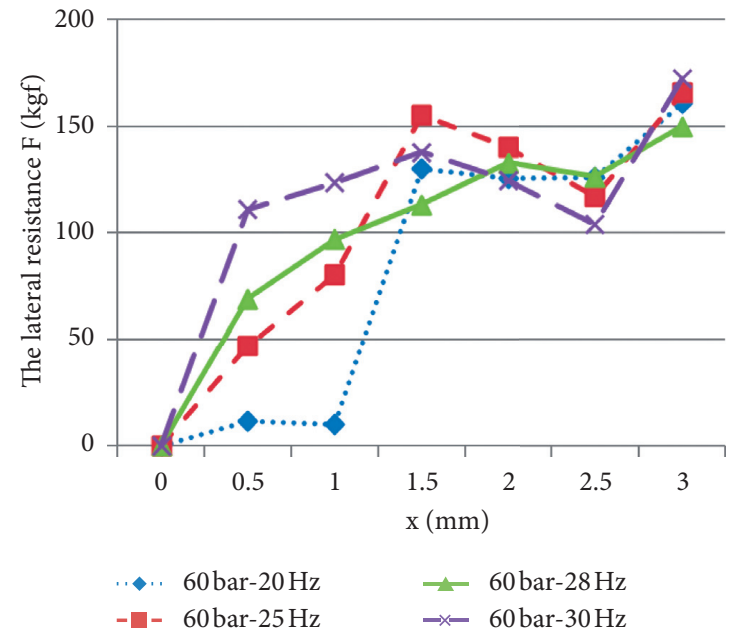

(b)

Figure 15: The curve of the lateral resistance under different frequencies and fixed pressures. 


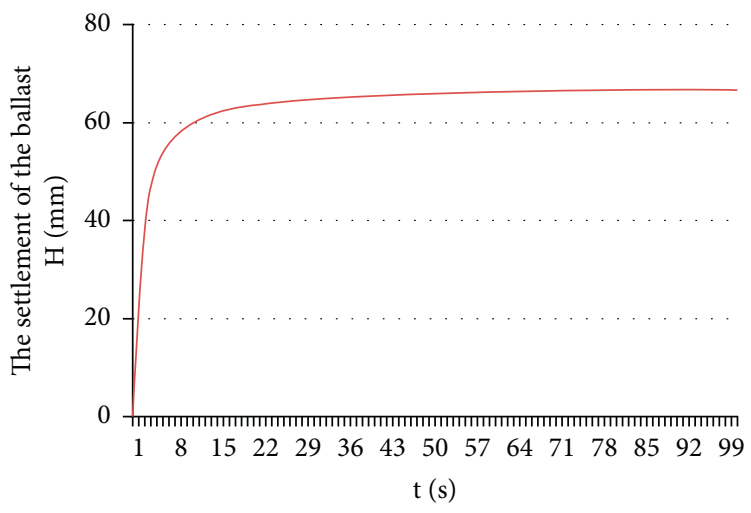

FIgURE 16: The curve of the settlement of the integrated ballast with the time.

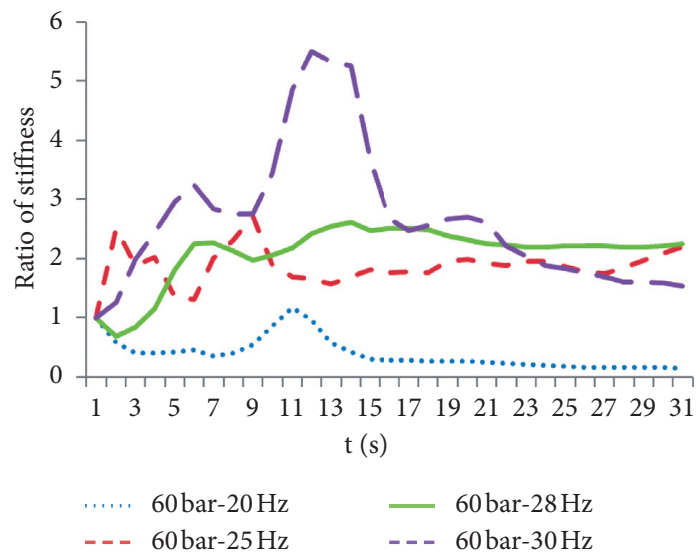

Figure 17: The curve of increase ratio of the sleeper support stiffness under different working conditions.

mentioned earlier, we have verified the consistency between the simulation results and the real situation, indicating that EDEM simulation has a good reference function and can be used to study the changes and development trends of the real situation. Therefore, it is feasible to use the EDEM software to simulate the operating process, as well as studying the influence on the stiffness of the sleeper support and the damping of the ballast bed under different working conditions of the dynamic track stabilizer.

In the simulations of previous scholars, the response of the running vehicle under the steady state of the ballast bed was studied. At this time, the dynamic characteristic parameters of the ballast bed are all equivalent parameters with fixed values. There is no research on the change of the dynamic characteristics of the ballast bed during the working process of the maintenance equipment. During the working process, the values of dynamic performance parameter for the ballast bed are constantly changing over time, but these parameter values cannot be easily measured. Therefore, it is necessary to study the change law of the dynamic characteristic parameters of the ballast bed during working process and propose a time function model of these parameters, which is very important to improve the accuracy of the simulation.
Through the above research, we have obtained the optimal operating parameters under a single factor influence. Therefore, we used simulation to study the change of the supporting stiffness with time under the pressure parameter that was fixed at 60 bar and the vibration frequency parameter that was fixed at $28 \mathrm{~Hz}$. Assuming that $K_{0}$ is the value of sleeper supporting stiffness after operation of the tamping vehicle, $K_{t}$ is the value of sleeper supporting stiffness after operation with the dynamic track stabilizer for $t$ seconds. For $B=K_{t} / K_{0}, B$ is the ratio of sleeper supporting stiffness before and after operation with the dynamic track stabilizer [22]. Based on the analysis data, the fitting curve of $\mathrm{B}$ with time was drawn under the working condition with the optimal operating parameters, as shown in Figure 18. The figure shows that the value of $B$ increases rapidly with time in the initial stage. Moreover, the increase of B value gradually stabilizes after 3 seconds. From Figure 16, it can be found that, after the operation time exceeds 30 seconds, the ballast bed basically no longer settles, and it reaches a relatively stable state. After that, the supporting stiffness of the sleeper and the damping of the ballast bed basically no longer change with time. The regression analysis was carried out by MATLAB software, and the functional model of sleeper supporting stiffness changing with time under operation with the optimal parameters was obtained: 


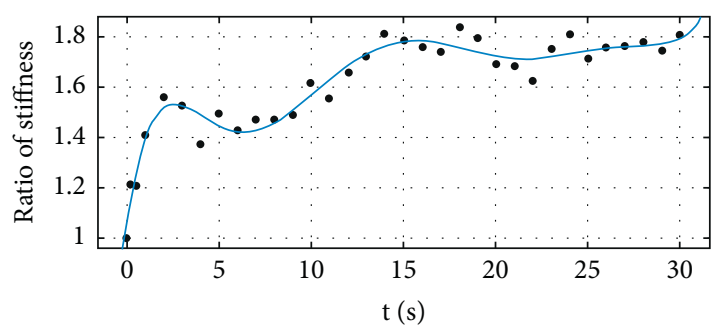

FIgURE 18: The ratio curve of the sleeper support stiffness.

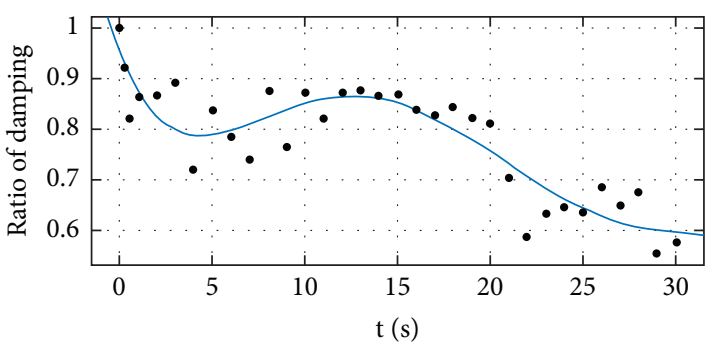

Figure 19: The ratio curve of ballast damping.

$$
K_{t}=\left(\begin{array}{c}
1.579 e^{-8} t^{7}-1.886 e^{-6} t^{6}+9.007 e^{-5} t^{5}-2.18 e^{-3} t^{4}+2.786 e^{-2} t^{3} \\
-1.775 e^{-1} t^{2}+4.928 e^{-1} t+1.049
\end{array}\right) K_{0}, \quad(0 \leq t \leq 30) .
$$

Similarly, assuming that $C_{0}$ is the value of ballast damping after operation of the tamping vehicle, $C_{t}$ is the value of ballast damping after operation with the dynamic track stabilizer for $t$ seconds. For $E=C_{t} / C_{0}, E$ is the ratio for the value of ballast damping before and after operation with the dynamic track stabilizer. Based on the analysis data, the fitting curve of $E$ with time was drawn under the working condition with the optimal operating parameters, as shown in Figure 19. The regression analysis was carried out by MATLAB software, and the functional model of the damping changing with time under working with the optimal operating parameters was constructed:

$$
C_{t}=\left(-3.45 e^{-7} t^{5}+3.401 e^{-5} t^{4}-1.19 e^{-3} t^{3}+1.709 e^{-2} t^{2}-9.259 e^{-2} t+0.9515\right) C_{0}
$$

We constructed the parameterized models $C_{t}$ and $K_{t}$ for the dynamic characteristics of the ballast bed, which provides an effective reference variable for improving the accuracy of the simulation of the vehicle-track coupling system.

\section{Conclusion}

In the paper, we have taken the WD-320 dynamic track stabilizer as a research target to study the acceleration response of the ballast bed during the operation, the influence of operating parameters on the quality state of the ballast bed, and the changing law of the supporting stiffness, damping, and subsidence of the ballast bed. We have found that $18-30 \mathrm{~Hz}$ is the effective range of vibration frequency parameter for the dynamic track stabilizer, and when the value of the vibration frequency parameter is between 25 and 30 , the quality state of the ballast bed is significantly improved. The optimal operating parameter of vibration frequency for the WD-320 dynamic track stabilizer is $28 \mathrm{~Hz}$. Moreover, the effective range of pressure parameter for the
WD-320 dynamic track stabilizer is $50-70$ bar, and the optimal operating parameter of pressure is 60 bar. Finally, we have constructed the parameterized models $C_{t}$ and $K_{t}$ for the dynamic characteristics of the ballast bed which can optimize the selection of operating parameters, which provides an effective reference variable for improving the accuracy of the simulation of the vehicle-track-subgrade coupling system. The above results revealed that it can improve the efficiency during railway maintenance and effectively solve the problem of less maintenance time caused by high traffic density.

\section{Data Availability}

The data were curated by the authors and are available upon request.

\section{Conflicts of Interest}

The authors declare that there are no conflicts of interest regarding the publication of this paper. 


\section{Acknowledgments}

This work was supported in part by KUST Talent Introduction Scientific Research Program (Grant nos. KKSY201855004 and KKSY201765024).

\section{References}

[1] S. Dietz, G. Hippmann, and G. Schupp, "Interaction of vehicles and flexible tracks by co-simulation of multibody vehicle systems and finite element track models," Vehicle System Dynamics, vol. 37, no. sup1, pp. 372-384, 2002.

[2] K. Popp, I. Kaiser, and H. Kruse, "System dynamics of railway vehicles and track," Archive of Applied Mechanics, vol. 72, no. 11, pp. 949-961, 2003.

[3] N. Chaar and M. Berg, "Simulation of vehicle-track interaction with flexible wheelsets, moving track models and field tests," Vehicle System Dynamics, vol. 44, no. sup1, pp. 921-931, 2006.

[4] W. M. Zhai, Vehicle Track Coupling Dynamics, Science Press, Beijing, China, Third edition, 2007.

[5] J. Oscarsson, "Dynamic train-track-ballast interaction with unevenly distributed track properties," Vehicle System Dynamics, vol. 37, no. sup1, pp. 385-396, 2002.

[6] J.-l. Xiao, H. Liu, J.-M. Xu, P. Wang, G.-Z. Liu, and R. Chen, "Longitudinal resistance performance of granular ballast beds under cyclic symmetric displacement loading," Journal of Zhejiang University-Science A, vol. 18, no. 8, pp. 648-659, 2017.

[7] F. D. Zhao, Dynamic Track Stabilizer, China Railway Press, Beijing, China, 2006.

[8] A. Kish and G. Samavedam, "Dynamic buckling of continuous welded rail track: theory, tests, and safety concepts," Transportation Research Record, vol. 29, no. 1289, pp. 23-38, 1991.

[9] M. Esmaeili, R. Nouri, and K. Yousefian, "Experimental comparison of the lateral resistance of tracks with steel slag ballast and limestone ballast materials," Proceedings of the Institution of Mechanical Engineers, Part F: Journal of Rail and Rapid Transit, vol. 231, no. 2, pp. 175-184, 2017.

[10] H. L. Yao, Z. Hu, Z. Lu, and H. Wang, "Analytical model to predict dynamic responses of railway subgrade due to highspeed trains considering wheel-track interaction," International Journal of Geomechanics, vol. 16, no. 2, p. 15, Article ID 0401506, 2016.

[11] L. A. Yang, W. Powrie, and J. A. Priest, "Dynamic stress analysis of a ballasted railway track bed during train passage," Journal of Geotechnical and Geoenvironmental Engineering, vol. 135, no. 5, pp. 680-689, 2009.

[12] G. Kouroussis and O. Verlinden, "Prediction of railway induced ground vibration through multibody and finite element modelling," Mechanical Sciences, vol. 4, no. 1, pp. 167-183, 2013.

[13] G. Kouroussis, D. Connolly, P. K. Vogiatzis, and O. Verlinden, "Modelling the environmental effects of railway vibrations from different types of rolling stock: a numerical study," Shock and Vibration, vol. 2015, p. 15, Article ID 142807, 2015.

[14] P. Alves Costa, R. Calçada, and A. Silva Cardoso, "Trackground vibrations induced by railway traffic: in-situ measurements and validation of a 2.5 D FEM-BEM model," Soil Dynamics and Earthquake Engineering, vol. 32, no. 1, pp. 111-128, 2011.
[15] C. H. Chiang and P. H. Tsai, "A numerical study of the screening effectiveness of open trenches for high-speed traininduced vibration," Shock and Vibration, vol. 2014, p. 15, Article ID 489090, 2014.

[16] W. Zhai, Z. He, X. Song, and X. Li, "Prediction of high-speed train induced ground vibration based on train-track-ground system model," Earthquake Engineering and Engineering Vibration, vol. 9, no. 4, pp. 545-554, 2011.

[17] P. Galvín, A. Romero, and J. Domínguez, "Vibrations induced by HST passage on ballast and non-ballast tracks," Soil Dynamics and Earthquake Engineering, vol. 30, no. 9, pp. 862873, 2010.

[18] W. M. Zhai, C. F. Zhao, H. Xia et al., "Basic scientific issues on dynamic performance evolution of the high-speed railway infrastructure and its service safety (in Chinese)," Science in China Series E-Technological Sciences, vol. 44, pp. 645-660, 2014.

[19] Y. X. Chou, Y. Gu, J. C. Liu et al., "Modelling arterial blood pressure waveforms for extreme bradycardia and tachycardia by curve fitting with Gaussian functions," International Journal of Modelling, Identification and Control, vol. 32, pp. 3-4, 2019.

[20] S. Wang, J. Na, and Q. Chen, “Adaptive predefined performance sliding mode control of motor driving systems with disturbances," IEEE Transactions on Energy Conversion, p. 1, 2020.

[21] Q. Chen, X. Yu, M. Sun, C. Wu, and Z. Fu, "Adaptive repetitive learning control of PMSM servo systems with bounded nonparametric uncertainties: theory and experiments," IEEE Transactions on Industrial Electronics, p. 1, 2020.

[22] B. Yan, Y. Y. Huang, B. Hu, and X. J. Wang, "Mechanical characteristics optimization of ballast bed variable on operating process for the dynamic track stabilizer," in Proceedings of the 9th International Conference On Modelling, Identification and Control, pp. 874-879, Kunming, China, July 2017.

[23] B. Yan, B. Hu, and Y. Y. Huang, "Prediction model with optimal matching parameters for a dynamic track stabilizer during railway maintenance," International Journal Modelling, Identification and Control, vol. 33, no. No. 4, pp. 369377, 2019.

[24] Y. Hao, Railway Engineering, China Railway Press, Beijing, China, 2000.

[25] S. G. Zeng, Railway Discrete Ballast Track, China Railway Press Publishers, Beijing, China, 1997.

[26] F. Chen, Research on Technical Measures to Improve the Speed of Railway Opening, Doctoral Dissertation, Beijing Jiaotong University, Beijing, China, 2007.

[27] G. M. Hu, Discrete Element Analysis and Simulation of Particle System, Wuhan University of Technology press, Wuhan, China, 2010. 